\title{
O PROCESSO DE EMPRESARIZAÇÃO EM ORGANIZAÇÕES CULTURAIS BRASILEIRAS
}

THE ENTERPRISATION PROCESS ON BRAZILIAN CULTURAL ORGANIZATIONS

\author{
Recebido em 14.05.2013. Aprovado em 18.03.2014 \\ Avaliado pelo sistema double blind review \\ DOI: http://dx.doi.org/10.12712/rpca.v8i1.286
}

\author{
Marcio Silva Rodrigues \\ marciosilvarodrigues@gmail.com \\ Universidade Federal de Pelotas - Capão do Leão - RS - Brasil \\ Rosimeri Carvalho da Silva \\ rosimeri.carvalho@ufrgs.br \\ Universidade Federal do Rio Grande do Sul - Porto Alegre - RS - Brasil
}

\section{Eloise Helena Livramento Dellagnelo}

eloise@cse.ufsc.br

Universidade Federal de Santa Catarina - Florianópolis - SC - Brasil

\section{Resumo}

Para Solé (2008), a empresa converteu-se no modelo universal dos indivíduos e demais organizações (processo de empresarização). Seguindo estes argumentos, consideramos relevante desenvolver um estudo com o objetivo de verificar os impactos do processo de empresarização em organizações esportivas e religiosas localizadas no Brasil. Para desenvolver essa pesquisa de natureza predominantemente qualitativa, coletamos dados por meio de entrevistas, observação direta e documentos diversos. Os dados foram analisados através da técnica de análise categorial de conteúdo. De uma maneira geral, analisamos quatro dimensões do processo de empresarização adaptadas de Solé (2004; 2008): orientação mercadológica, aspectos legais, linguagem e organização do trabalho. A análise dos dados revela que os clubes de futebol são as organizações que, quando comparados com os outros dois tipos, apresentaram o processo de empresarização mais intenso e avançado.

Palavras-chave: Empresarização. Empresa. Futebol. Voleibol. Igrejas.

\section{Abstract}

According to Solè (2008), currently, the enterprise became in the universal model to the individual and the other organizations (enterprisation process). Following these arguments, we consider important to develop a study to verify the impacts of process enterprisation in sports and religious organizations located in Brazil. To develop this predominantly qualitative research, we collected data through interviews direct observation and other documents. Data were analyzed using the technique of categorical content analysis. In general, we analyze four dimensions of the adapted process enterprisation Solé $(2004 ; 2008)$, marketing orientation, legal aspects, language and organization of work. Data analysis reveals that soccer clubs are organizations that, when compared with the other two types, the process of enterprisation showed more intense and advanced.

Keywords: Enterprisation. Enterprise. Soccer. Volleyball. Churches. 


\section{Contextualizações Iniciais}

A empresa se transformou no único modelo possível para as organizações construídas pelos homens? Podemos dizer que todas as organizações estão se transformando em empresas à medida que incorporam a lógica mercantil e, em conseqüência, tomam a eficiência como seu valor predominante? Partimos de tais questionamentos com o intuito de demonstrar que "com a modernidade, a primazia econômica torna-se cada vez mais pesada; orienta, perturba, influencia as outras ordens. Exagera as desigualdades, encerra na pobreza ou na riqueza os coparticipantes da economia-mundo, atribui-lhes um papel e, ao que parece, por muito tempo" (BRAUDEL, 1996, p. 37). À primeira vista, essa situação sinaliza para a "vitória", supremacia ou hegemonia do aspecto econômico frente a outros aspectos, como a política e a cultura que, anteriormente, compunham a sociedade em outras proporções e faz com que nossa sociedade experimente um processo qualitativamente novo de subordinação das finalidades tradicionais, situadas fora do mercado, às exigências do cálculo e ao lucro monetário (BOURDIEU, 1979).

Como reflexos iniciais dessa "nova" configuração social, Guerreiro Ramos (1989) argumenta que no passado nenhuma sociedade esteve jamais na situação da sociedade desenvolvida centrada no mercado como em nossos dias, na qual o processo de socialização está, em grande parte, subordinado a uma política cognitiva exercida por vastos complexos empresariais que agem sem nenhum controle. Nesse sentido, parece evidente que se o mercado tornou-se o principal enclave da sociedade moderna, ao definir o "ponto de vista" a partir do qual a realidade é aprendida e como cada um deverá posicionar-se, tal instituição tornou-se, de certa maneira, a modeladora da mente dos cidadãos. Em decorrência disso, definir, atualmente, o que pertence e o que não pertence a um espaço dito de predominância econômica tornou-se tecnicamente impossível, uma vez que outros campos como a arte, o lazer e a religião foram marcados ou condicionados por e para objetivos econômicos.

Além disso, diferentes autores têm identificado alguns importantes princípios que formaram a base ideológica da sociedade moderna (o individualismo, o economicismo, o utilitarismo, a racionalização, dentre outros), os quais acreditamos, encontraram na moderna empresa capitalista sua via material de personificação e disseminação. Assim, a empresa, forma predominante do mundo capitalista moderno quando disseminada pelo processo de globalização, acarreta na imposição de um mundo sobre todos os outros e na distorção de todas as organizações e de todas as relações pela lógica empresarial e pelo discurso da gestão que acompanha este modelo. Como afirmou Solé (2000, p. 104), "pela primeira vez na história da humanidade, um mundo está em vias de conquistar o planeta inteiro, de conseguir suprimir todos os outros mundos, sem exceção. Um mundo que se apropria dos outros, este é o sentido que propomos dar à expressão mundialização, globalização. A modernização do mundo é a vitória, total, do mundo moderno".

As discussões realizadas por estes autores e a realidade com a qual nos defrontávamos no decorrer de nossas pesquisas nos levou a buscar na teoria de Andreu Solé (2008) sobre o processo de empresarização do mundo, tanto uma maneira de compreender melhor o que percebíamos, como uma forma de guiar nossa análise. De acordo com esse autor, a singularidade de nossa sociedade reside, atualmente, na organização que a caracteriza, a empresa e, por isso, nosso mundo é um mundo-empresa. Assim, quando percebemos a estreita relação entre o mercado e a empresa (o desenvolvimento de um implica no desenvolvimento de outro) e, também o fato de que o modelo empresarial encontra-se subjacente à maioria das teorias organizacionais já desenvolvidas, assim como sua expansão e adoção por um grande número de organizações, é possível conceber que as considerações desenvolvidas nos parágrafos precedentes podem ser explicadas a partir de um fenômeno denominado 
empresarização. Segundo Solé (2008), esse fenômeno é caracterizado pela crescente influência que as empresas ou que o modelo empresarial exerce sobre os seres humanos e suas diversas organizações.

De fato, ao calcar-se em pressupostos de eficiência, qualidade, resultados e perpetuação, a empresa tem se firmado como o modelo organizador de todas as atividades humanas, responsável tanto por propor uma nova dinâmica ao indivíduo e às relações sociais (modificação da lógica de ação) como por disseminar a "boa nova" da modernização do mundo e das ferramentas para "ajudar" as organizações a se transformarem em empresas. É assim que no Brasil, atualmente, não é raro encontrar organizações voltadas a atividades não comerciais adotando características que anteriormente eram exclusivas das empresas, ou seja, algumas delas começam a utilizar a linguagem, os métodos, as ferramentas das empresas e, além disso, começam a pautar suas atividades em uma lógica de concorrência e transformam o benefício econômico em objetivo principal.

Essa questão torna-se ainda mais complexa se considerarmos sua influência sobre organizações, como as culturais, que estão fortemente relacionadas com o processo de construção da identidade de grupos, comunidades e nações (identidade social). Com esta compreensão, neste estudo, o tema é utilizado como um meio para examinar os impactos do processo de empresarização em organizações esportivas e religiosas localizadas no sul do Brasil. Pretendemos com esta investigação: (1) contribuir com os estudos e reflexões acerca da desconfiguração de práticas tradicionais, substantivas, geradoras da identidade de comunidades com uma grande carga simbólica; e (2) auxiliar no combate (resistência) à centralidade do mercado, demonstrando as perversões geradas pelo mesmo.

Como forma de sistematizar o objetivo proposto, inicialmente realizamos, a partir de Solé (2008), uma breve discussão acerca da centralidade da idéia de empresa em nosso mundo e do processo de empresarização. A partir desta discussão, esclarecemos a forma como esse trabalho foi operacionalizado explicitando nossa abordagem metodológica. Em seguida, desenvolvemos, a partir de dados coletados durante três anos de pesquisa, a análise de cada um dos tipos de organizações pesquisadas, a saber: as igrejas, o voleibol e o futebol. Por fim, após uma síntese geral do trabalho, realizamos nossas últimas reflexões e críticas sobre este tema.

\section{Sobre a Empresa e o Processo de Empresarização do Mundo}

A nossa sociedade é uma sociedade de organizações afirma Etzioni (1967). Tal afirmação, talvez pela confusão existente entre o que é realmente uma empresa e o que é uma organização, ou pela crescente onda de privatizações que transformaram organizações públicas em empresas privadas, ou ainda, pela introdução de ferramentas empresariais de gestão nessas organizações, modificaram, definitivamente, as características da nossa sociedade e principalmente dessas organizações. De acordo com essa perspectiva, pode-se afirmar que a nossa não é uma sociedade de organizações, mas sim de empresas. Solé $(2004 ; 2008)$, tentando evidenciar a predominância da empresa, levanta algumas questões: não é freqüentemente em uma clínica privada - uma empresa - que abrimos os olhos pela primeira vez? Que tipo de organização nos forma para o trabalho? Quais são as organizações que nos divertem? Não é a televisão, o cinema etc? Não se tratam de empresas? Nossa sociedade não é uma sociedade de empresas? Sendo assim, nossa sociedade reside, atualmente, na singularidade da organização que a caracteriza, a empresa. 0 mundo é o mundo das empresas, pois elas nos divertem, ensinam-nos, fornecem alimentos, vestem-nos etc; ou seja, as empresas determinam toda a atividade da sociedade, esse mundo é denominado, por Solé (2008), mundo-empresa.

Mas o que é empresa? Para Pareto (1996), a empresa é a organização que reúne os elementos da 
produção e que os dispõe de maneira a realizá-la. Esses elementos da produção provêm, em parte, dos indivíduos, como, por exemplo, o trabalho e certos produtos; em parte também de outras empresas, como, por exemplo, certos produtos que devem servir para a materialização de uma corrente única, o produto. Independente dos fins de uma empresa, ela sempre busca obter uma vantagem e quase sempre essa vantagem é medida em dinheiro (PARET0, 1996). Uma outra contribuição ao referido tema é a percepção de Weber. De acordo com Weber (2004) uma ação economicamente orientada, baseada no cálculo utilitário das conseqüências, passa a se legitimar em toda a sociedade e em especial no seio das organizações, onde a noção de maximização do retorno esperado passa a assumir uma posição de natureza imperativa. Sendo assim, segundo esse autor, a moderna empresa capitalista baseia-se fundamentalmente no cálculo e pressupõe um sistema administrativo e legal cujo funcionamento pode ser racionalmente calculado, em princípio pelo menos, em virtude de suas normas gerais fixas, exatamente como o desempenho previsível de uma máquina. De maneira mais simplificada, pode-se dizer que uma empresa é um sistema de atividade contínua perseguindo um fim de uma espécie definida (WEBER, 1987; WEBER, 2004).

Buscando eliminar a confusão existente entre o uso do termo organização no lugar do termo empresa, mas com o primeiro carregando o significado do segundo, Solé (2008), parte da pergunta de Ronald Coase sobre o que é uma empresa e apresenta as peculiaridades que uma empresa possui perante outras organizações. De acordo com Solé (2008), a distinção da empresa diante das demais organizações é verificada a partir de cinco postulados gerais. Para o autor a empresa é: (1) um conjunto - singular - de relações entre humanos; (2) um fenômeno social total, ou seja, é uma organização econômica, social, política, psicossocial, jurídica, etc, o que supõe um enfoque transdisciplinar; (3) é uma organização histórica, ou seja, não é natural ao ser humano, surgiu no tempo, em determinado momento e pode vir a desaparecer; (4) uma organização característica e fundamental do mundo que se considera moderno e desenvolvido; a empresa organiza este mundo, sendo assim, as relações que caracterizam a empresa são aquelas que caracterizam o mundo; e (5) como toda organização humana, a empresa é um evento contingente da história humana que poderia ter tomado outro rumo e que não deveria necessariamente a empresa aparecer.

Antes de efetivamente caracterizar uma empresa, parece-nos necessário discorrer acerca da influência das empresas no mundo de hoje. Para ponderar sobre esta questão, recorremos ao quarto postulado de Solé: a empresa é uma organização característica e fundamental deste mundo.

Segundo Solé (2008), atualmente, o modelo empresarial se converteu no modelo universal de organização das atividades humanas. Este modelo, apoiado em pressupostos de eficácia, qualidade, resultados e perpetuação, é visto pelas organizações como um exemplo a ser seguido. Sendo assim, não é raro encontrar, em organizações brasileiras, a presença de um comportamento empresarial, numa busca para se adequarem a estes pressupostos, talvez por medo de não acompanhar as mudanças que estão ocorrendo em diversas organizações inseridas em seus contextos ou setores de atuação como, por exemplo, os clubes europeus. Segundo Powel e Dimaggio (1991), talvez por pressões isomórficas do ambiente, o comportamento empresarial passa a ser adotado por organizações que anteriormente não possuíam essa característica. Assim, a linguagem, os métodos, as ferramentas, as técnicas, as práticas das empresas penetram cada vez mais nas organizações que se pode, razoavelmente, considerar como não sendo empresas (SOLÉ, 2008).

Essa situação evidencia o que Solé (2008) denomina de empresarização do mundo. Segundo ele, essa expressão é utilizada para caracterizar a crescente influência que as empresas exercem 
sobre os seres humanos e as demais organizações. Contudo, Solé (2008) salienta que não se conseguiu imaginar outra possível forma/modelo universal de organização que não a empresa porque o discurso ainda vigente (e, sobretudo forte) é o de que todas as organizações humanas devem se organizar como a empresa. Sendo assim, podemos assumir que a empresa é a principal instituição desta sociedade e a responsável por criar grande parte de nossas necessidades.

Na busca por estabelecer um conceito transdisciplinar sobre o que é uma empresa, Solé (2004; 2008) argumenta que esta é constituída a partir de um conjunto de traços. Esses traços foram concebidos a partir do método de construção de um tipo ideal preconizado por Max Weber. Este tipo ideal é caracterizado por uma construção do pesquisador, uma "pintura do pensamento", ou seja, jamais será observado em sua forma pura (WEBER, 2004). Segundo Solé (2004; 2008), cada um dos traços apresentados é uma condição necessária, mas não suficiente para se falar em empresa. É o conjunto dos traços que formam a empresa. Como se trata de uma teoria transdisciplinar, cada traço apresenta ao mesmo tempo características das mais diversas áreas, não tendo, portanto, um caráter exclusivamente, econômico, social ou político.

Sendo assim, Solé $(2004 ; 2008)$ caracteriza a empresa como um conjunto humano, mais ou menos estável, vasto ou reduzido, mais ou menos concentrado, podendo desaparecer a qualquer o momento; de propriedade privada; salarial; uma relação dirigente/dirigido; que possui divisão do trabalho; que produz e implica desemprego; que implica e produz o indivíduo; submetida ao direito, às leis; sujeita a outra organização: o Estado; onde a propriedade e a direção podem estar juntas ou separadas; que é uma mercadoria; onde a atividade é única ou múltipla; que concebe, produz e vende mercadorias; que concorre permanentemente com outras empresas; que supõe outra organização: o mercado; sendo um processo de criação destrutiva de relações incertas entre humanos; com moeda, capital e benefício econômico; com escritura e contabilidade; que produz linguagem, seres humanos insatisfeitos e uma concepção de felicidade.

Este conjunto de traços do tipo ideal de empresa inclui aspectos bastante amplos que merecem investigações específicas. Além disso, a teoria da empresarização está em construção, evoluindo com os próprios estudos de Sole. Por estas razões, para analisar o processo de empresarização das organizações que integram este estudo, agrupamos alguns traços formadores da empresa (11 no total), propostos por Solé $(2004 ; 2008)$, em quatro dimensões, a saber: orientação mercadológica, aspectos legais, linguagem e organização do trabalho. Apresentamos, no quadro abaixo, os traços selecionados, bem como uma breve descrição dos mesmos.

\section{Quadro 1: Dimensões do processo de empresarização}

\begin{tabular}{|c|c|c|}
\hline Categoria & Traços & Detalhamento \\
\hline \multirow{2}{*}{$\begin{array}{l}\text { Orientação } \\
\text { mercadológica }\end{array}$} & $\begin{array}{l}\text { A empresa é uma organização que } \\
\text { concebe, produz e vende } \\
\text { mercadorias }\end{array}$ & $\begin{array}{l}\text { Aponta quais são os produtos e } \\
\text { serviços, onde eles são } \\
\text { comercializados e para quem. }\end{array}$ \\
\hline & $\begin{array}{l}\text { A empresa é uma organização que } \\
\text { concorre permanentemente com } \\
\text { outras empresas. }\end{array}$ & $\begin{array}{l}\text { Descreve quem são os } \\
\text { concorrentes do clube e que ações } \\
\text { são tomadas para evitar essa } \\
\text { concorrência. }\end{array}$ \\
\hline
\end{tabular}




\begin{tabular}{|c|c|c|}
\hline & $\begin{array}{l}\text { A empresa é uma organização que } \\
\text { supõe outra organização: o } \\
\text { mercado }\end{array}$ & $\begin{array}{l}\text { Descreve como é e como se forma } \\
\text { o relacionamento com os } \\
\text { parceiros. }\end{array}$ \\
\hline & $\begin{array}{l}\text { A empresa é uma organização com } \\
\text { moeda, capital e benefício } \\
\text { econômico }\end{array}$ & $\begin{array}{l}\text { Refere-se a forma como são } \\
\text { obtidos os recursos necessários } \\
\text { para o funcionamento do clube, } \\
\text { bem como indica a preocupação, a } \\
\text { busca e em quais ações a } \\
\text { organização tem por fim o } \\
\text { resultado financeiro. }\end{array}$ \\
\hline \multirow{3}{*}{$\begin{array}{l}\text { Aspectos } \\
\text { legais }\end{array}$} & $\begin{array}{l}\text { A empresa é uma organização com } \\
\text { escritura e contabilidade. }\end{array}$ & $\begin{array}{lcr}\begin{array}{l}\text { Descreve } \\
\text { contábeis }\end{array} & \text { quais os } & \text { registros } \\
\text { organização. } & & \\
\end{array}$ \\
\hline & $\begin{array}{l}\text { A empresa é uma propriedade } \\
\text { privada. }\end{array}$ & $\begin{array}{l}\text { Formalização como entidade } \\
\text { jurídica. }\end{array}$ \\
\hline & $\begin{array}{l}\text { A empresa é uma organização } \\
\text { submetida ao direito, às leis e está } \\
\text { sujeita ao Estado }\end{array}$ & $\begin{array}{l}\text { Identifica quais os instrumentos } \\
\text { legais que regem a atividades das } \\
\text { organizações, bem como a } \\
\text { maneira que está configurada a } \\
\text { sua relação com o Estado. }\end{array}$ \\
\hline Linguagem & $\begin{array}{l}\text { A empresa é uma organização que } \\
\text { produz linguagem. }\end{array}$ & $\begin{array}{l}\text { A linguagem básica utilizada na } \\
\text { empresa e que seja própria da } \\
\text { empresa ou de setores da } \\
\text { empresa que indica a } \\
\text { incorporação da linguagem } \\
\text { empresarial na organização. }\end{array}$ \\
\hline \multirow{3}{*}{$\begin{array}{l}\text { Organização } \\
\text { do Trabalho }\end{array}$} & $\begin{array}{l}\text { A empresa é uma organização } \\
\text { salarial }\end{array}$ & \multirow{3}{*}{$\begin{array}{l}\text { Refere-se à } \text { relação } \\
\text { assalariado/voluntariado dentro } \\
\text { dessas organizações e as questões } \\
\text { ligadas a complexidade estrutural } \\
\text { dessas organizações (número de } \\
\text { participantes, hierarquia, divisão } \\
\text { do trabalho). }\end{array}$} \\
\hline & $\begin{array}{l}\text { A empresa é uma relação } \\
\text { dirigente/dirigido }\end{array}$ & \\
\hline & $\begin{array}{l}\text { A empresa possui divisão do } \\
\text { trabalho }\end{array}$ & \\
\hline
\end{tabular}

Fonte: Elaborado pelos autores

Nosso estudo é uma pesquisa descritivo-interpretativa, predominantemente qualitativa, realizada a partir da técnica de estudo de multi-caso, tendo como unidade de análise organizações esportivas e religiosas, quais sejam: dois clubes de voleibol participantes da Superliga de Voleibol Brasileiro (Santa Catarina Voleibol Clube - SCVC e Unisul Sport Club UNISUL) no ano de 2004, dois clubes de futebol, na época, participantes da Primeira Divisão do Campeonato Brasileiro (Figueirense Futebol Clube - FFC e Sport Club Internacional - SCI) e três igrejas pertencentes ao protestantismo histórico, pentecostal e neopentecostal (Primeira Igreja Batista de Florianópolis - PIB, Igreja Evangélica Assembléia de Deus - AD e Igreja Universal do Reino de Deus - IURD) - todas as organizações estudadas são registradas formalmente como 
entidades sem fins lucrativos, e existem, com exceção dos clubes de voleibol, há pelo menos três décadas.

Fruto da associação de diversas investigações que constituem uma das propostas de trabalho do grupo interinstitucional de pesquisa denominado Observatório da Realidade Organizacional, a opção por estas e não outras organizações justifica-se, primeiramente, pelo esforço de compreender, dentro de determinado espaço de tempo, as transformações que estão ocorrendo no campo da cultura no Brasil. Nesse processo, tomamos tal campo como aquele composto por organizações "que constroem o sentido de identidade pelo que expressam, seja por meio das artes, danças, cantos e músicas, dos esportes e da religião" (CARVALHO e ANDRADE, 2006, p. 2) e buscamos, a partir de diversas perspectivas teóricas, compreender os impactos da inquietação levantada por tantos estudiosos acerca da invasão do mercado e da forma empresa naquelas organizações, isto é, em organizações que tradicionalmente não apresentavam tais características. Desse modo, enquanto alguns pesquisadores discutem tal fenômeno sob o prisma da mercantilização ou da teoria institucional, outros o abordam a partir da perspectiva de Solè $(2004 ; 2008)$. Por consequência, como todos os pesquisadores que optaram por essa última situavam-se, durante a coleta de dados, em Santa Catarina, por questões de acesso e de recursos, a maior parte das organizações investigadas, selecionadas levando em consideração justamente a possibilidade de evidenciar os impactos do processo de empresarização em diferentes espaços, áreas e/ou campos de atuação, também estão localizadas naquele estado. A exceção foi o Sport Club Internacional, o único clube gaúcho a participar da primeira divisão do Campeonato Brasileiro de 2005, incluído com o intuito de realizar uma análise comparativa do processo evidenciado no representante catarinense na competição daquele ano.

Desenvolvida a partir de dados, primários e secundários, relativos a três anos de estudos naquelas organizações, nesta pesquisa resgatamos a atuação das organizações pesquisadas ao longo de sua história (perspectiva longitudinal com corte seccional). Para coleta de dados primários, com o objetivo de adquirir a maior diversidade possível na escolha dos entrevistados, buscamos, a partir de entrevistas semi-estruturadas, obter informações daqueles membros que possuíam maior conhecimento sobre o assunto ou maior representatividade perante outros membros nessas organizações, tais como: presidentes, diretores, gerentes, técnicos, sacerdotes, atletas e outros funcionários ou voluntários, respeitando as especificidades de cada tipo de organização. Como se trata de um trabalho qualitativo, o número de entrevistados não foi definido a priori. Além destas entrevistas, os dados primários foram complementados por meio da observação direta em reuniões, treinos, cultos, jogos e no cotidiano das organizações. Realizamos ainda um levantamento de documentos para obtenção de dados secundários. Este levantamento foi realizado internamente nas organizações em seus regimentos internos, estatutos, atas de reuniões, documentos contábeis, informativos internos e externos, folhetos, revistas especializadas, sites, programas de televisão e de rádio, relatórios ou outros documentos pertinentes. Levantamento documental em outras organizações que dispuseram de dados secundários sobre o fenômeno em estudo também foi efetuado, como por exemplo, federações, patrocinadores, entre outros. Por fim, no que concerne a análise de dados, utilizamos a análise de conteúdo, especificamente a técnica da análise categorial (BARDIN, 1988).

\section{Reflexos do Processo de Empresarização em Organizações Brasileiras}

Nesta sessão, a partir das dimensões de empresarização definidas no Quadro 1 (orientação mercadológica, aspectos legais, linguagem e organização do trabalho), discutimos a presença e os impactos da adoção de características empresariais nas organizações selecionadas. 
No que concerne à análise da dimensão Orientação Mercadológica procuramos identificar como essas organizações percebem os fiéis (no caso das igrejas) e os torcedores (no caso dos clubes de voleibol e futebol), quais os produtos e serviços oferecidos por essas organizações, onde eles são comercializados, quais são as fontes de recursos financeiros, se existe uma preocupação em obter lucro, como está configurado o relacionamento dessas organizações com outras, presentes no mercado e como está caracterizada a concorrência entre as mesmas. Em relação aos Aspectos Legais, nossa análise assentou-se na tentativa de clarificar as questões relativas à natureza jurídica, os registros e responsabilidades legais e a preocupação/orientação com questões contábeis (formalização financeira e o uso da contabilidade na tomada de decisão). Sobre a Linguagem, procuramos identificar a presença de termos da linguagem empresarial em tais organizações. Por fim, no que diz respeito à Organização do Trabalho, discutimos as questões relativas à organização salarial (relação assalariado/voluntário), a divisão do trabalho (profissionalização, especialização das atividades) e outros temas relacionados à estruturação dessas organizações (complexidade, coordenação e centralização).

Apresentamos, a seguir, os principais resultados da análise de cada um dos tipos de organizações selecionados para este estudo.

\section{O preço da salvação: a empresarização das Igrejas}

A análise de igrejas protestantes justifica-se no contexto brasileiro pela proliferação vertiginosa de tais organizações em todo o território nacional. Segundo o Instituto Brasileiro de Geografia e Estatística - IBGE (2002), o percentual de brasileiros que se identificam como evangélicos cresceu 6\% entre 1991 e 2000, configurando 15,4\% da população, ou seja, o segundo maior percentual. Esta proliferação parece ser acentuada em regiões ou locais nos quais os indicadores sócio-econômicos são mais baixos. Ou seja, há uma atuação crescente deste tipo de organização e esta atuação busca se consolidar junto às camadas mais pobres da população, embora não exclusivamente. Edward (2002) informa que o mercado impulsionado pelos protestantes movimenta 3 bilhões de reais e gera pelo menos 2 milhões de empregos.

Com base nos dados relativos a análise de três igrejas protestantes localizadas na cidade de Florianópolis (Primeira Igreja Batista de Florianópolis - PIB, Igreja Evangélica Assembléia de Deus - AD e Igreja Universal do Reino de Deus - IURD), podemos observar que, em síntese, a Igreja Batista possui uma fraca presença de preocupações relativas à economia monetária e um baixo uso da linguagem empresarial ao longo de sua história. Também observamos um aumento na presença de sujeitos empregados nessa igreja. Na Assembléia de Deus a preocupação com as questões relativas à economia monetária é mediana ao longo do tempo. 0 uso da linguagem empresarial torna-se forte com o tempo. A força do mercado torna-se mais forte na igreja, por meio do comércio com outras organizações. Já na Universal a presença das dimensões da empresarização pode ser caracterizada como mediana desde o começo de sua história. Elas se tornam mais fortes com o passar do tempo. Observamos que as questões relativas ao mercado e à linguagem já estão fortemente presentes na organização desde sempre.

No que concerne à Orientação Mercadológica, mais especificamente na questão relativa à produção de mercadorias e serviços concretizada a partir de seu intercâmbio com moeda corrente, verificamos que apenas a Universal concebe, produz e comercializa mercadorias, mesmo de natureza religiosa e simbólica, explicitamente com esse fim. Suas práticas confirmam a relação mercadológica fornecedor-cliente, tanto pela oferta temática e especializada, em suas reuniões diárias, de produtos e serviços de caráter terapêutico e taumatúrgico, como pela comercialização aberta de bens materiais, seja também nos seus templos ou pela Internet. A moeda de troca na primeira situação apontada tem origem nos dízimos e ofertas dos fiéis, que vêem a aquisição das mercadorias mágico-religiosas, condicionada às suas contribuições 
financeiras. Por outro lado, no caso da Igreja Batista e da Assembléia de Deus, ainda que, com algumas variações, possuam basicamente as mesmas propostas de bens e serviços religiosos em relação à Universal, a forma como conduzem a oferta de suas mercadorias tem sido diferente em suas trajetórias. 0 tratamento dado pelas duas primeiras igrejas a essa questão, faculta aos seus fiéis o direito de retribuir ou não, com qualquer moeda, pelo usufruto do que lhes foi ofertado. Essa desobrigação de uma contrapartida justifica dizer que, ao que tudo indica, a natureza religiosa dessas organizações tem prevalecido ante a possibilidade de orientação por uma lógica mercadológica.

Já a agenda semanal de reuniões da Universal é organizada tematicamente a cada dia da semana, com cultos que se baseiam nitidamente na oferta especializada de serviços religiosos, de cunho terapêutico e taumatúrgico. Seus discursos são centrados na doutrina da teologia da prosperidade, cujas propostas incluem a concessão divina para a prosperidade material, cura física e emocional, superação de problemas. Nos discursos durante os cultos, ressalta-se que a posse das bênçãos está condicionada à doação financeira (dízimos e ofertas). Em praticamente todos os cultos assistidos, percebe-se a recorrência a frases do tipo: "se você der, será abençoado", "se você ofertar, Deus te retribuirá dez vezes mais", "quando nós pegamos o pouco que temos [sobre o dinheiro] e colocamos nas mãos de Deus, ele é fiel conosco".

No caso da Universal, o trecho de seu web site destacado a seguir evidencia sua relação com a comercialização de produtos diversos:

Desperte emoções com uma recordação inesquecível. A perfeita harmonia entre a nobreza do ouro e a força do aço". Coleção de Jóias Universal. Ouro 18k com aço inox AISI 304, antialérgico e resistente a impactos. Design exclusivo. Qualidade internacional com certificado de garantia. Desenvolvida por equipe especializada na criação de jóias. Parte dos royalties será revertida às obras assistenciais da IURD. Acompanha linda embalagem de veludo para presente. Somente $5 x \mathrm{R} \$ 17,40$ sem juros cada unidade.

Ademais, afora a Universal que complementa sua renda com a comercialização de diversos produtos e serviços, a principal fonte de recursos financeiros são os dízimos e as ofertas dos fieis. Além disso, em relação à busca por lucro, ou seja, a obtenção de benefício econômico, em tese, devido à natureza legal dessas igrejas, nenhuma delas deveria repartir dividendos entre os seus dirigentes ou acumular lucros com o exercício da atividade religiosa. Esse parece ser o caso da Igreja Batista e da Assembléia de Deus, visto que nesta investigação não se têm subsídios para afirmar o contrário. No entanto, as práticas não convencionais, para os moldes eclesiásticos, de tratamento dos recursos financeiros da Universal, têm dado provas dos seus ganhos monetários. Prova disso, são os investimentos dessa igreja em diferentes segmentos comerciais lucrativos. Pelo que observamos, com base na análise dos indicadores apresentados, nem todas as igrejas analisadas tornaram-se, nitidamente, economicamente orientadas. Contudo, particularmente a Universal, demonstra em todos os campos de sua atuação, uma maior adequação aos parâmetros empresariais nesta dimensão de análise.

Ao analisarmos a relação dessas organizações com outras organizações presentes no mercado, admitimos que a pluralidade de propostas religiosas, no mesmo espaço, contribui para a geração de um mercado com intensa disputa entre as organizações que o compõem. Consideramos que a simples presença no campo religioso, já faz dessas entidades, via de regra, participantes de um amplo mercado, onde diferentes confrarias ofertam produtos e serviços religiosos similares, e por essa razão, competem entre si para criar demandas e ter a adesão de fiéis. A análise comparativa feita aqui expõe o posicionamento e a lógica de ação dessas igrejas frente a essa evidência. Ressaltamos que na análise interna sobre economia monetária, apenas o 
comportamento da Universal, configura uma situação de mercado, como a que é vista na relação fornecedor-cliente.

A análise externa revela que somente a Igreja Batista mantém uma postura de isolamento e abstenção quanto à concorrência e relação comercial com outras entidades. Mesmo possuindo vínculo com outras instituições denominacionais, visando parcerias para consecução de objetivos comuns, nos últimos dez anos, a igreja tem exclusivamente concentrado suas ações internamente. Prova disso, é o seu proselitismo limitado no âmbito dos seus cultos. Assim sendo, não há evidências que configurem alguma relação de mercado dessa igreja com qualquer outra entidade congênere ou mesmo outra religião.

De outro modo, constatamos diversas similitudes no modo de atuação entre a Assembléia de Deus e Universal. A começar pelo arrojo dos seus proselitismos, que caracterizam explicitamente suas intenções em adquirir e garantir presença nos espaços onde atuam. Tais ações evangelísticas são focadas no mesmo público, em geral, de baixa renda e com pouca escolaridade, fato que inclusive, as torna, concorrentes diretas. Além disso, constata-se suas relações mercantis com outras entidades, também em conseqüência dos seus intuitos em granjear maior alcance de pessoas, desta vez através de canais midiáticos. Ambas as igrejas, possuem contratos comerciais com veículos de comunicação de rádio e tevê. No caso da Universal, além de possuir seus próprios canais, 21 no momento da pesquisa, ainda ocupa espaços em outras emissoras. Os resultados da análise indicam que há um processo de empresarização mais forte nessas duas igrejas, do que na Igreja Batista, no que diz respeito a esta dimensão de análise.

Em relação aos Aspectos Legais, verificamos que as três igrejas analisadas assemelham-se, em constituição jurídica e variedade de documentos legais. Todas elas são legalmente constituídas junto ao Cadastro Nacional de Pessoas Jurídicas - CNPJ, sob os termos de sociedades civis religiosas sem fins lucrativos. Entre os registros que fazem parte do rol de instrumentos legais dessas igrejas, encontram-se os seus balanços contábeis; estatutos constitutivos, explicitando suas formações administrativas; regimentos internos, regulando os processos organizacionais; contratos de trabalho com os seus funcionários; escrituras públicas dos seus imóveis e os contratos de locação de imóveis, caso apenas da Assembléia de Deus e da Universal, que possuem templos alugados em diversas localidades. Ressaltamos que no caso da Universal, não há divulgação pública, nem mesmo aos seus membros, de demonstrativos das suas movimentações financeiras. Com base nos dados levantados, os resultados indicam que, apesar da elevação do volume de procedimentos e registros legais nessas organizações, não se pode afirmar que haja fortes indícios nas igrejas, que as configure, no dizer de Solè (2008), como um conjunto de relações legais entre humanos ou as distingue como em conformidade a um processo de empresarização. Concluímos que esta dimensão não é relevante para a análise deste tipo de organizações, pois sua atuação implica, necessariamente, o atendimento a certas exigências legais. No entanto, no que diz respeito ao modelo de empresa, é importante destacar que a principal relação mantida por estas organizações, o vínculo com os fiéis, não é baseada em contratos ou outras formas previstas legalmente.

Nas questões relativas ao tipo de Linguagem utilizado nessas organizações, mediante a audição de programas de rádio e tevê, a participação nas reuniões das igrejas e por ocasião das entrevistas realizadas, observamos nos interlocutores, a referência e a ocorrência de expressões com caráter empresarial. Em todas as igrejas, percebemos que a linguagem utilizada, em geral, envolve um padrão característico do ofício eclesiástico. Apesar da predominância do discurso religioso, observa-se que em diferentes graus, as entidades investigadas sinalizam alguma identificação com as expressões empresariais. 
Além disso, evidenciamos que na Igreja Batista, a expressão verbal empregada hoje, diferentemente de alguns anos passados, quando, por exemplo, ainda não se falava em planejamento estratégico, demonstra uma discreta aproximação com a linguagem comumente utilizada no mundo corporativo. Em relação às outras igrejas, apesar do intenso uso de jargões típicos do evangeliquês, como no caso da Assembléia de Deus e da teologia da prosperidade, caso da Universal, não se pode deixar de considerar a linguagem publicitária e o esforço de propaganda, que essas igrejas empregam para atrair e reunir fiéis para divulgação dos seus preceitos, como uma manifestação da linguagem empresarial, uma vez que o sistema de mídia dessas organizações esteja focado para despertar no seu público-alvo, o desejo de aquisição dos produtos e serviços por elas oferecidos.

Por fim, nos aspectos relativos à Organização do Trabalho, nos três casos analisados, fica evidente ao longo dos anos, a elevação do contingente de pessoal a serviço das igrejas. Tanto a mão-de-obra remunerada, quanto a voluntária aumentou de modo expressivo em todas essas organizações. Com o aumento do número de membros, novas demandas por serviço surgem e requerem a criação e preenchimento de novas áreas de trabalho. Esses recém-criados espaços, não somente incorporam mais atividades de cunho religioso, para consecução direta dos seus fins constitutivos, como também, parecem implicar no incremento de diferentes atividades de apoio e suporte aos objetivos estabelecidos pelas igrejas. Em geral, as igrejas pesquisadas assemelham-se na proporcionalidade de pessoal remunerado em relação ao número de voluntários. No entanto, comprovamos uma discrepância quando se trata da proporcionalidade do voluntariado em relação ao número total de membros dessas organizações. Destaque para as diferenças entre a Igreja Batista e a Assembléia de Deus. Enquanto a primeira apresenta um percentual de $40 \%$ do seu total de membros envolvidos com o trabalho voluntário na igreja, na Assembléia de Deus esse índice não chega a $1 \%$ dos seus fiéis. Diante da constatação do incremento de pessoal remunerado, associado ao considerável grau de profissionalização verificado, admite-se, quando se trata isoladamente da dimensão emprego, que todas as igrejas analisadas vem passando no decorrer dos anos, por um processo gradual de empresarização.

O processo de empresarização se desenvolveu pontualmente em diferentes estágios e intensidades em cada igreja investigada. Todas elas apresentaram claros indícios de adequação aos parâmetros empresariais utilizados neste trabalho. Em razão disso, podemos concluir que as três organizações encontram-se inseridas em um processo de empresarização. A Primeira Igreja Batista de Florianópolis é a organização no qual este processo é menos perceptível, seguida pela Igreja Evangélica Assembléia de Deus com um processo um pouco mais evidente. A Igreja Universal do Reino de Deus é a organização que apresenta de modo mais claro todos os traços de empresarização analisados.

\section{Uma grande "sacada": o processo observado no voleibol}

Outro tipo de organização que procuramos analisar com relação ao processo de empresarização foram clubes esportivos, principalmente o voleibol e o futebol. 0 voleibol é um esporte que há alguns anos vem se desenvolvendo intensamente no Brasil, notadamente a partir do momento em que a seleção brasileira de voleibol alcançou os melhores resultados nos campeonatos internacionais (Jogos Olímpicos e Liga Mundial) - um dos marcos da notoriedade do voleibol no Brasil pode ter sido a conquista do ouro olímpico em 1992. 0 futebol, como é notório, é o esporte mais popular do país. Nesse sentido, no que concerne ao processo de empresarização do voleibol brasileiro, analisamos o que ocorre em dois clubes que participaram da Superliga Nacional de 2005, Santa Catarina Voleibol Clube (SCVC) e Unisul Sport Club (Unisul). Ademais, antes de efetivamente tecer nossas considerações acerca da "realidade" identificada nesses clubes, gostaríamos de ressaltar que, diferentemente dos outros tipos de organização (Igrejas e 
Clubes de Futebol), os dados acerca do Santa Catarina e da Unisul são mais escassos. No entanto, as informações constantes no sitio da Confederação Brasileira de Voleibol já indicam a importância do esporte e do processo de empresarização quando afirma que,

Outra grande virada no jogo veio após a posse de Ary Graça Filho, em 07/01/97. Com seu pioneirismo e sua busca incansável pela perfeição, trouxe à CBV a Era Empresarial e de inúmeros títulos. Além de manter o voleibol como segundo esporte na preferência nacional, o profissionalismo já adquirido na gestão anterior só fez evoluir. Ex-jogador da seleção, advogado e empresário com vasta experiência no mercado financeiro, Ary adotou um novo modelo de gestão para a $\mathrm{CBV}$, administrando-a de fato como empresa. Ao considerar o voleibol um produto, torcedores e o público em geral viraram clientes e as Federações Estaduais, Prefeituras e Empresas, parceiras. Assim, a CBV é a responsável pela administração do negócio.

As conquistas do esporte são, portanto, relacionadas à gestão empresarial que os dirigentes imprimiram à confederação. É bastante provável que isto tenha influenciado as organizações esportivas que analisamos. Uma análise histórica dessas organizações permite-nos perceber que, dadas as dimensões selecionadas para este estudo, verificamos uma intensidade maior de características empresariais na Unisul, quando comparada a Santa Catarina, ou seja, apesar de identificarmos mudanças muito sutis em praticamente todas as dimensões analisadas, tais mudanças não fizeram frente àquelas ocorridas na Unisul, principalmente no que concerne a aspetos de relacionamento e concorrência com outras organizações presentes no mercado (Orientação Mercadológica). Enquanto na Santa Catarina o processo de empresarização ficou mais evidenciado nas questões legais e de organização do trabalho, na Unisul esse processo, talvez devido às parcerias firmadas, além de mais intenso, provocou alterações na Orientação Mercadológica, nos Aspectos Legais, na Linguagem e na Organização do Trabalho.

Pormenorizando cada uma das respectivas dimensões, apesar de não identificarmos, claramente, uma intensa comercialização de produtos/serviços ou a tentativa de tratar os torcedores como clientes, como será visto a seguir com o caso das organizações futebolísticas, entendemos que, conforme mencionado, a relação da Unisul com seu patrocinador pode ter implicado na intensidade com que o processo de empresarização apresenta-se nessa organização. Dizemos isso, pois, desde a sua criação a Unisul Esporte Clube apresenta relações com uma empresa, uma vez que nasce de uma parceria entre a Universidade do Sul de Santa Catarina e a Olympikus, que trouxe para Florianópolis sua equipe de voleibol. A primeira vista, tal parceria parece exercer uma grande influência (financeira, política e de mercado) nas atividades dessa organização, uma vez que, de acordo com os entrevistados, o patrocinador interfere, diretamente, tanto nas decisões do clube como no retorno do investimento, fato que, apesar de possuir um patrocinador, não acontece, tão evidentemente, na Santa Catarina tão evidentemente, devido a sua singela preocupação em continuar a equipe. Pode-se perceber a proximidade entre o patrocinador e o processo de empresarização, no relato de alguns entrevistados evidenciando que o contrato de imagem dos atletas é essencial para a Olympikus, uma vez que o atleta, ao tornar-se um instrumento de Marketing, auxilia na garantia do retorno do investimento da mesma.

Percebe-se que a relação com o patrocinador afeta as dimensões analisadas, dentre elas destacamos também os Aspectos Legais. Partindo do exemplo mencionado no parágrafo anterior, parece claro que, ao desenvolver ações orientadas para a exploração da imagem dos atletas, a Olympikus serve-se de um grande número de registros legais, buscando assegurar maiores garantias no cumprimento de suas determinações comerciais. No caso da Santa Catarina, mesmo não apresentando um processo de empresarização tão intenso quanto a Unisul, 
também percebemos um incremento no número de registros legais adotados pelo clube.

O uso da Linguagem empresarial é outra conseqüência da forte influência do patrocinador nas equipes, principalmente na Unisul, as quais vêm, cada vez mais, incorporando em sua linguagem diversos termos empresariais. Observamos situações nas quais expressões típicas de empresas eram utilizadas tais como: marketing, endomarketing, planejamento estratégico e oportunidades de negócios. Podemos perceber, no entanto, que os termos empregados são mais tradicionais na área de gestão e menos ligados a modismos do que aqueles que aparecem no discurso dos entrevistados das organizações de futebol, como veremos adiante.

Em relação à Organização do Trabalho, consideramos relevante salientar que ambas as organizações apresentaram mudanças significativas e muito parecidas ao longo do tempo. Por exemplo, é possível auferir que o Santa Catarina, ao longo de sua trajetória, apresentou um crescimento no número de pessoas envolvidas no clube com a abertura de equipes de base. No entanto, esta abertura não teve reflexos sobre a destinação de recursos, sendo que o incremento do número de atletas não gerou aumento no número de assalariados. No que se refere à relação dirigente/dirigido e a divisão do trabalho, verificamos que, sob o primeiro ponto, tanto no Santa Catarina como na Unisul existe uma pequena diferenciação vertical, caracterizada por um reduzido número de cargos entre o topo e a base das referidas organizações. Do mesmo modo, enquanto na área administrativa dessas organizações verificamos uma divisão do trabalho difusa, devido ao acúmulo de funções por alguns membros do clube (Santa Catarina) ou pela existência de cargos meramente formais dentro da organização (Unisul), na área técnica de ambas organizações, a divisão do trabalho acontece de forma clara, determinação de áreas específicas de trabalho e delegação explícita de funções - constatações que remetem ao caráter profissional da equipe técnica em oposição as outras áreas da organização. Por último, gostaríamos de frisar que, em todas as áreas dessas organizações, o ajuste mútuo entre os membros e a supervisão direta constituem-se nos mecanismos básicos de coordenação utilizados.

Por fim, afora a constatação de que o processo de empresarização foi mais intenso na Unisul, consideramos relevante alertar para o fato de que, atualmente, vários autores citam o esporte como um dos negócios mais lucrativos do mundo, sendo utilizado como estratégia de marketing de várias organizações. Nesse contexto, o voleibol veio buscando esse espaço no mundo dos negócios esportivos, e através da associação com empresas passou a competir neste ramo dos negócios com outras modalidades como o futebol. Os clubes esportivos, utilizando as possibilidades legais de atuarem como entidades sem fins lucrativos, passam a buscar parceiros para viabilizar os seus objetivos. Os estatutos das organizações pesquisadas apresentam cláusulas que identificam essa opção pelo terceiro setor, determinando as atividades que podem ser desenvolvidas pela organização como atividades de lazer, sociais, culturais e de rendimento. 0 que se percebe, no entanto é que o maior foco dessas organizações esportivas é o esporte de rendimento, ficando as atividades sociais como segunda prioridade. Supõe-se que isso ocorra devido à dificuldade em se obter recursos para a área social, onde o retorno pode ser mais lento e não há uma exposição tão forte na mídia como os grandes campeonatos esportivos. As organizações patrocinadoras parecem visualizar os clubes esportivos como uma oportunidade de investimento, como estratégia mercadológica, para ter um retorno em seus negócios. Dessa forma, estabelecem uma relação de troca com as organizações e não de doação de valores. Diante dessas reflexões, parece fácil supor que tais organizações esportivas tendem a se profissionalizar cada vez mais, se quiserem sobreviver no ambiente em que estão envolvidas, pois as influências são evidentes, e não só por parte dos patrocinadores, mas de todos os setores que compõem o campo do voleibol catarinense e nacional. 


\section{Clientes ou torcedores? o caso dos clubes de futebol}

Dentre todas as organizações analisadas neste estudo, os clubes de futebol representam, sem dúvida, aquelas que mais sofreram com os impactos do processo de empresarização do mundo. Nos parágrafos subseqüentes, apresentamos uma breve síntese de uma pesquisa realizada com dois clubes que, na época de realização do estudo, participavam da Primeira Divisão do Campeonato Brasileiro, a saber: Figueirense Futebol Clube e Sport Club Internacional.

A força do processo de empresarização nos clubes de futebol evidencia-se logo na análise referente aos aspectos próprios da Orientação Mercadológica, quando, por exemplo questionamos aos entrevistados sobre como tais organizações percebem os seus torcedores. Tanto o Figueirense como o Internacional entendem que a relação entre o clube e os torcedores, pelo menos na perspectiva dos clubes, foram modificadas ao longo do tempo. Para os entrevistados, a antiga relação clube-torcedor foi alterada para clube-cliente. Além disso, embora os clubes enxerguem os torcedores como consumidores do futebol e, em alguns momentos, desejem que os torcedores também passem a se ver como clientes, em outros, a manutenção do status de torcedor, que é movido por paixão, é interessante para que os clubes possam alavancar suas ações comerciais, conquistar a lealdade e transformá-los em clientes. Mais que isso, ao considerarem os torcedores como clientes, como o cálculo utilitário tornou-se predominante, a avaliação da lealdade de um torcedor é medida a partir da relação desses com o consumo dos produtos e serviços oferecidos pelas organizações (intensidade e repetição de compras). Nessa relação, as decisões do torcedor restringem-se à quantidade a comprar, pois ele estará sujeito a consumir sem tirar vantagem de uma hipotética disputa de preços entre concorrentes, própria de outros mercados.

Considerando a perspectiva de que os torcedores são clientes e incorporando o comportamento empresarial, os clubes passam a oferecer-lhes produtos e/ou serviços. Durante as entrevistas, quando questionados a respeito do principal produto ou serviço oferecido, todos os entrevistados foram unânimes em responder que o principal serviço oferecido por estas organizações é a partida de futebol. A partida de futebol por toda magnitude que possui, além de ser a via mais direta de comercialização do futebol, cumpre uma outra função muito importante para os clubes no que diz respeito à comercialização de outros produtos e serviços.

Em relação aos produtos comercializados para os torcedores, atualmente, empresas passaram a licenciar produtos identificados com a marca do clube e oferecê-los para os torcedores, como uma forma de tornar mais concreto ou complementar o espetáculo futebolístico. A partir de estratégias de comunicação, a comercialização desses artigos assenta-se na perspectiva de que o uso desses produtos torna os torcedores mais leais e mais próximos ao clube. Desse modo, além da comercialização de partidas de futebol, esses clubes, na época da pesquisa, ofereciam uma gama de outros produtos e serviços para seus torcedores (clientes), que vão desde produtos complementares em dias de jogos (bebidas, lanches, camarotes) até a comercialização de roupas com um estilo "casual" - cerca de 130 produtos no Figueirense e 200 no Internacional.

Consideramos relevante fazer uma breve reflexão sobre outro produto comercializado entre os clubes de futebol: o atleta. Segundo os entrevistados de ambos os clubes, devido à elevada valorização do futebol no mundo e ao aumento das cifras envolvidas em tal esporte, os jogadores de futebol transformaram-se em mercadorias valiosas tanto por sua habilidade como atleta como por sua capacidade de atrair mais recursos para os clubes e outras organizações envolvidas com o esporte ou não (instrumentos de marketing).

Ainda em relação à análise da Orientação mercadológica, buscamos compreender como se configura o comportamento dessas organizações no relacionamento com outras organizações 
presentes no mercado. Nesse contexto, percebemos que esses estão muito mais próximos, em termos de semelhanças de objetivos e de comportamentos, das organizações empresariais do que de outros tipos de organizações. Assim, por força da empresarização, esses clubes substituem a paixão e o amadorismo pela racionalidade e pelo profissionalismo na gestão. A manutenção do relacionamento com as organizações do mercado passa a ser norteada por princípios inspiradores de confiança nas relações comerciais, como: credibilidade, visibilidade e viabilidade econômica. A adoção dessa postura prima, essencialmente (senão, unicamente), pela questão financeira, ou seja, pela possibilidade dessas organizações obterem maiores resultados financeiros.

Da mesma forma que acontece em pelo menos um dos clubes de voleibol (Unisul), além de patrocinadores, essas organizações possuem alguns parceiros de gestão. Dentre todos os parceiros citados por ambas as organizações, é importante fazer referência ao principal parceiro do Figueirense: a Figueirense Participações S/A. Consolidada em 2004, a referida empresa de capital fechado começou a ser planejada, formada e constituída em 1999. Segundo os entrevistados, é a responsável pela gestão de praticamente todo o clube, cabendo a ela realizar a administração da área comercial, do futebol e da marca do clube. Apontada pelos entrevistados como a responsável pelo sucesso financeiro e esportivo do clube, essa empresa tem a incumbência de ampliar o "mix" de negócios do clube, captar potenciais investidores, desenvolver a marca Figueirense e consolidar o Figueirense como uma das principais equipes do futebol brasileiro.

Nos dois clubes, Figueirense e Internacional, devido à massificação da informação e ao poder de penetração social dessas organizações, foi exaltada a importância da mídia como o principal elemento de promoção do esporte e de exposição dos clubes ao público em geral. Porém, enquanto no Figueirense, mesmo sabendo da sua importância, os entrevistados afirmam que o relacionamento com a mídia é muito delicado e, por vezes, conturbado, no Internacional, esse relacionamento é aproveitado por todos os membros como um instrumento de geração de riqueza tanto para o clube quanto para os membros dessas organizações (utilização da mídia nos negócios particulares dos integrantes dessas organizações)

Da mesma forma como acontece no relacionamento dessas organizações com outras presentes no mercado, no que diz respeito à concorrência com outros clubes, identificamos que o foco é, principalmente, competir com os times de futebol do mesmo estado. Sendo assim, a disputa entre essas organizações, desconsiderando a rivalidade dentro de campo, fica restrita a praticamente duas condições: busca por espaço, visibilidade e oportunidade de negócios e a ampliação do número de torcedores. 0 relato a seguir evidencia as estratégias utilizadas pelos clubes, neste caso, pelo Figueirense:

Desde 98, nós estamos fazendo com que a nossa torcida cresça com base numa proposta de marketing [...] nesse projeto a gente procura, desde o início, fazer com que a criança opte pelo Figueirense, pois como é um cliente que fideliza muito fácil, a gente realiza um trabalho com as escolas e com outras instituições da Grande Florianópolis. As crianças vêm ao clube, assistem a um vídeo institucional, ganham lanche, ganham kit, visitam o estádio, conhecem alguns jogadores [...] a partir desse momento, a gente está ganhando esse cliente. Isso vai se refletir daqui a dez anos, quando estes torcedores estiverem na arquibancada do estádio [...] esses torcedores jovens serão aqueles que terão um período muito longo de consumo de produtos do clube [...] depois desse tempo, não adianta o pessoal do Avaí vir ao Figueirense para tentar convencer esse torcedor. 
Em relação à análise dos Aspectos legais, considerando a valorização que o aspecto financeiro possui dentro dessas organizações, percebemos que a contabilidade cumpre duas funções: uma fiscal e outra gerencial. No que diz respeito ao uso da contabilidade para cumprir exigências fiscais, tanto o Figueirense como o Internacional elaboram e publicam, todos os anos, o balanço patrimonial, o demonstrativo de resultado do exercício, o demonstrativo das mutações do patrimônio líquido e o demonstrativo das origens e aplicações de recursos. Cumprindo a sua outra função, a contabilidade tem o propósito de fornecer informações que possam ser usadas como elementos de suporte à tomada de decisão, ou seja, ela é usada como uma ferramenta gerencial. Sobre essa questão, o Internacional mostrou-se muito mais preocupado com o controle de suas contas (elaboração mensal do controle das informações financeiras) com vistas a reduzir os custos do clube.

0 relato a seguir também evidencia a procura crescente pelo registro de marcas para sua exploração comercial: "Saci, Alma Colorada, Inter Sport, SCI, Colorado, Parque Gigante, Vermelho e Branco (que nós utilizávamos para fazer os bailes vermelho e branco em todo o estado) [...] todas essas marcas são registradas, mas, independente do registro, hoje, a lei assegura a exploração comercial dessas marcas vinculadas ao clube. Isso também se aplica aos atletas do clube, ou seja, esses também não precisam de registros para o clube explorar a sua imagem".

Outrossim, em relação a sujeição dessas organizações às leis e ao Estado, os relatos coletados permitem assumir que, quanto mais o futebol ou a exploração do futebol vai adquirindo um caráter de atividade econômica, maior o número de responsabilidades legais impostas pelo Estado. Desse modo, embora essas organizações estejam classificadas como entidades civis sem fins lucrativos, são tratadas, para fins de controle e fiscalização, como empresas. Além dessa determinação, muitas outras existem com o propósito de regular as atividades dessas organizações. Assim, os clubes, por força da lei, vêem-se obrigados a atender essas exigências, porém, demonstrando a sua inclinação comercial, associam o cumprimento dessas leis a estratégias de marketing. Por exemplo, o Estatuto do Torcedor prevê a setorização do estádio, a garantia de ingressos com lugares pré-determinados, o aumento da segurança nos estádios, a higiene das instalações. Os clubes, por sua vez, cumprem essas determinações, mas revertem, talvez, por desinformação dos torcedores, em estratégias de marketing (valorização e/ou incremento do produto) utilizadas com o objetivo de atrair o maior número de "clientes" ao estádio.

A análise da presença da Linguagem empresarial nos clubes de futebol não consiste em identificar quais expressões ou palavras de cunho empresarial são utilizadas, mas qual a intensidade de seu uso nessas organizações, pois é evidente sua presença marcante em ambas. Embora os dois clubes apresentem tal característica, e, em alguns casos, o Internacional possua uma linguagem mais empresarizada; no contexto geral a presença e a intensidade da linguagem empresarial foi mais evidente no Figueirense. Sendo assim, no Figueirense Futebol Clube, talvez por ser óbvia a cobrança por crescimento, por desempenho e por resultados financeiros, realizada pelos membros da Figueirense Participações, e/ou devido ao fato de que alguns dos entrevistados, além de dirigentes do clube, sejam acionistas dessa empresa, em muitos relatos identificou-se uma preocupação e uma menção constante de palavras ou expressões como: eficiência, eficácia, gestão da marca, visibilidade da marca e resultado.

Os trechos a seguir selecionados de relatos dos entrevistados são bons exemplos deste uso. Na linguagem de marketing identificaram-se discursos como: "[...] os clubes, para seguirem, têm que fazer negócios, melhorar o seu mix de produtos, buscar sócios, desenvolver ações que tragam rentabilidade para o clube, desenvolver ações que gerem a fidelização do associado. [...] 
eu uso essas informações como uma forma de pesquisa de mercado como qualquer produto". Na linguagem dos financistas, "nós temos uma série de relatórios gerenciais [...] o balanço patrimonial, o demonstrativo do resultado do exercício, o demonstrativo das mutações do patrimônio líquido, e depois nós temos uma série de outras análises.[...] as vezes, a gente contrata um jogador a um preço muito alto e, quando chega a hora de vender, não consegue ter um retorno do investimento". E, por último, na linguagem dos funcionários de recursos humanos, a discrepância entre ambos os clubes desapareceu, salientado-se, dentre outras, as seguintes falas: “(..) a rotatividade de funções não é tão grande [...] nós estamos começando a fazer trabalhos, capacitar funcionários, começamos a nos preocupar com os benefícios dos funcionários [...] com o estabelecimento de procedimentos padrões para cada área, com a descrição do cargo de cada funcionário".

Na medida em que uma organização se torna empresarizada, reduz-se o número e a participação dos voluntários que a criaram e, em contrapartida, eleva-se o número de trabalhadores assalariados. Considerando-se as organizações estudadas, observamos que o voluntariado está presente somente nos altos escalões dos clubes, nas posições de presidentes e vice-presidentes. Em outros aspectos relativos à estrutura dessas organizações, a análise realizada permitiu compreender que, mesmo estando em diferentes estágios de estruturação, esses clubes procuram, constantemente, readaptar seu desenho aos objetivos estabelecidos. Assim, decorrente das novas concepções desse esporte, ou seja futebol como um produto, as principais modificações estruturais dessas organizações estão relacionadas ao processo de coordenação de suas atividades.

Podemos concluir que os dois clubes de futebol, Figueirense e Internacional, apresentam fortes traços empresariais. 0 Sport Club Internacional apresenta um grau de empresarização maior que o Figueirense Futebol Clube. Ainda que um dos principais fatores responsáveis pela intensificação do processo de empresarização nessas organizações tenha sido a Lei Pelé (de 1998), as informações levantadas permitem deduzir que o Sport Club Internacional trilha por esse caminho há muito mais tempo, ou desde o início dos anos 80. Conseqüentemente, por ser regido há mais tempo por uma lógica empresarial, o Internacional possui um processo de empresarização bem mais elaborado. Essa organização apresenta, tanto para os processos, métodos, ferramentas quanto para os procedimentos de cunho empresarial, formas mais sofisticadas de gestão e, portanto, mais próximas de um comportamento empresarial. Além disso, o Internacional possui outras características, existentes em poucas empresas, ainda não encontradas no Figueirense Futebol Clube, como: a preocupação com a segmentação de clientes, a utilização de relatórios contábeis como mecanismos de controle dos custos, fortes estratégias, objetivos e ações da Vice-Presidência de Marketing, a adesão ao Programa Gaúcho de Qualidade e Produtividade, o estabelecimento da missão, da visão, do conceito de negócio e de princípios do clube, dentre eles está a "Busca da excelência", a preocupação com o mercado latinoamericano e preocupação com questões de responsabilidade social como estratégia de marketing.

Por fim, se procuramos compreender as características essenciais desse processo, é possível afirmar que, por ser um fenômeno social total, evidentemente, a adoção de uma lógica empresarial não é uma "virtude" somente das organizações futebolísticas pesquisadas. Os relatos dos entrevistados mostram indícios do processo de empresarização em praticamente todos os clubes participantes da Primeira Divisão do Campeonato Brasileiro e, arriscamos a dizer que, com diversas variações, devido à tendência ao comportamento isomórfico, é um fenômeno comum a muitos clubes não inclusos nesse grupo. Assim, considerando que o sucesso em uma competição está norteado, principalmente, pela variável financeira e que as cifras envolvidas em tal esporte aumentam à medida que esses clubes tornam-se mais empresarizados 
ou vice-versa, independente de qual seja o objetivo dessas organizações, seu "sucesso" dependerá da capacidade em obter, cada vez mais, recursos financeiros. Sendo assim, entendese que, seja qual for o objetivo do Figueirense ou do Internacional, uma vez empresarizados, cria-se um ciclo "sem fim" no qual o alcance de um determinado objetivo está intimamente relacionado com sua capacidade de prover ou captar maior quantidade de recursos financeiros, "aprisionando" tais organizações a um "mundo" no qual, eleva-se, como fim último e, talvez, único, a ênfase na obtenção de recursos financeiros. Esta passa a ser a condição sine qua non, delimitando ou impossibilitando o desenvolvimento de outras atividades ou objetivos organizacionais, bem como determinando qual o contexto de atuação dessas organizações, se local, regional, nacional ou global.

\section{Reflexões e Amarrações Finais}

A aproximação com as organizações estudadas nos ajudou a evidenciar um processo crescente de empresarização na maioria dos casos. Há, no entanto, diferenças quanto à intensidade com que o mesmo se fez presente. Em comparação com as organizações analisadas, os clubes de futebol, seja pela popularidade do esporte ou pelo contexto no qual estão inseridos, foram os que mais sofreram com os impactos do processo de empresarização. No voleibol, o caso da Unisul é mais evidente, embora ambas equipes já surjam dentro de uma perspectiva de negócio, principalmente do ponto de vista dos atletas e da organização patrocinadora. As igrejas evangélicas, por sua vez, parecem em um processo mais lento de empresarização, exceção feita para a situação encontrada na Igreja Universal do Reino de Deus.

Salientamos que a reflexão acerca das situações menos empresarizadas ainda carece de referencial teórico mais sólido para dar suporte a sua análise. Temos predominantemente teorias relativas ao fenômeno da adaptação, da submissão das organizações ao modelo empresarial. Talvez o voleibol esteja menos empresarizado pelo fato de pertencer a um tipo de esporte menos difundido no país, com menor número de praticantes, com um público mais reduzido e, conseqüentemente, com um mercado potencialmente menos expressivo. As igrejas atuam no campo religioso, aquele relativo ao conforto espiritual, um espaço que pode parecer ainda mais protegido das oportunidades empresariais. Por essa razão, tais organizações podem representar um desafio maior para os pesquisadores, na medida em que seu discurso possibilita aos membros e interessados neste mercado, dissimular a relação direta com as práticas empresariais.

Passando a analise de cada uma das categorias discutidas neste trabalho, percebemos que os aspectos relacionados à análise da Organização do Trabalho e dos Aspectos Legais estão presentes desde o início da constituição de todas as organizações em estudo. Destacamos, entretanto, que nestas situações os registros formais e os documentos contábeis se proliferam, tomando parte importante inclusive na tomada de decisão, como no caso dos clubes participantes do Campeonato Brasileiro de futebol (Figueirense e Internacional). Além disso, também observamos que o crescimento dessas organizações, por implicar na contratação de um número maior de pessoas, em um maior número de contratos (como é o caso das organizações esportivas) ou em uma expansão geográfica, acarreta na necessidade de incrementar os aspectos relacionados à formalização.

Maior destaque, no entanto, pudemos perceber no que diz respeito à evolução das dimensões diretamente relacionadas à linguagem empresarial e a orientação mercadológica. Sobre essa última, os casos do Figueirense e do Internacional, seja pela infinidade de produtos licenciados, pela noção de concorrência ou pela constante busca por recursos, tornam-se tão evidentes que dispensam elucubrações. No Voleibol, afora o volume crescente de produtos licenciados, o caso da Unisul, em especial, ilustra como a força do patrocinador pode aproximar a organização de 
um comportamento empresarial. Para além do dízimo, as igrejas, notadamente a Universal, também investem no desenvolvimento de produtos e/ou serviços como forma de complementar suas receitas. Em relação a concorrência entre essas organizações e/ou a ampliação de fieis, somente a Igreja Batista mostrou-se distante desse comportamento. De maneira geral, em todos os casos que quanto mais intenso é o processo de empresarização maior é o esforço para se comunicar, por diferentes meios, com o público (associado ou não), bem como a ênfase atribuída as relações com outras organizações (busca por patrocínio ou visibilidade). No caso das igrejas, a propriedade de veículos de mídia é, sem dúvida, um destaque.

Em relação às características relativas à organização do trabalho, pudemos verificar que o comportamento das igrejas e dos clubes de futebol foram aqueles que mais se aproximaram do modelo empresarial. As equipes de voleibol, por sua vez, caracterizam-se por um processo bastante incipiente. São movimentos diferentes, que, de certa forma, nos remetem a reflexões acerca da importância das dimensões mais fortemente relacionadas ao processo de empresarização das organizações. Isto é, nos parece que as dimensões mercado e linguagem são essenciais na discussão sobre o referido tema ao passo que, para os tipos de organizações selecionados, a organização do trabalho e os aspectos legais não demonstram a mesma centralidade para a evidenciação do processo.

Por fim, gostaríamos de ressaltar que a transformação de organizações não empresariais dentro de uma forte lógica de mercado remete-nos a importantes reflexões quanto às transformações para a realidade do esporte e das religiões, principalmente para as comunidades locais. As relações clube-torcedor, igreja-fiel tendem a se contaminar cada vez mais pela lógica mercadológica do sujeito como cliente. Os aspectos financeiros tendem a preponderar na tomada de decisão, provavelmente a lógica instrumental deve prevalecer neste caso. A predominância deste modelo em organizações antes caracterizadas por valores importantes no desenvolvimento de laços comunitários pode destruir significados compartilhados fundamentais na formação da identidade dos grupos, além de ter um forte impacto na relação dos indivíduos e na sua própria constituição. Desta forma, a busca desesperada de meninos por oportunidades de enriquecimento através do esporte os leva a se colocarem como produtos comercializáveis. 0 forte domínio das igrejas protestantes e o processo crescente de empresarização da Igreja Universal também tem influência em camadas pobres da população que, envolvidas pelo desespero causado pela ausência total de perspectiva em que parecem lançadas, caem na armadilha da busca de salvação, para suas vidas além de suas almas, através do estabelecimento de laços fortes com tal organização, laços que são considerados tão mais fortes quanto mais a relação se concretiza economicamente, através do consumo e do dízimo.

Os impactos deste processo vão muito além do que nos propomos analisar neste artigo, tentamos aqui mostrar o quanto organizações que originalmente pareciam razoavelmente distantes das relações de mercado, vêm desenvolvendo transformações no sentido da sua empresarização. Acreditamos que, a partir de agora, nossa agenda de pesquisa se direciona para um maior avanço na análise dos impactos desse processo.

\section{Referências}

BARDIN, L. Análise de conteúdo. Lisboa: Edições 70, 1988.

BOURDIEU, P. La Distinction: critique sociale du jugement. Paris: Les Editions de Minuit, 1979.

BRAUDEL, Fernand. Civilizaçao Material, Economia e Capitalismo - estruturas do cotidiano, 
v.1. São Paulo: Martins Fontes, 1996.

CARVALHO, C. A. P.; ANDRADE, J. A. de. A Inevitável Conversação entre Estudos Organizacionais e Administração Pública. Reflexões a Partir de uma Agenda de Pesquisa. In: Anais Eletrônicos do $30^{\circ}$ Encontro da Associação Nacional de Programas de Pós-Graduação em Administração, Salvador - BA, 2006.

EDWARD, José. A força do Senhor. VEJA, 3 de julho de 2002. Disponível em: http://veja.abril.com.br/030702/p_088.html. Acesso em 14/04/2011.

ETZIONI, A. Organizações Modernas. São Paulo: Pioneira, 1967.

GUERREIRo RAMOS, A. A Nova Ciência das Organizações. Rio de Janeiro: Fundação Getúlio Vargas. 1989.

PARETO, V. Manual de Economia Política São Paulo: Nova Cultural, 1996.

POLANYI, K. A grande transformação Rio de Janeiro: Campinas, 2000.

POWELL, Walter W E DIMAGGIO, Paul J. The iron cage revisited: institucional isomorphism and collective rationality. IN: POWELL e DIMAGGIO (Ed). The new institutionalism in organizational analysis. Chicago, The University of Chicago Press, 1991.

SCHUMPETER, J. A. A Teoria do Desenvolvimento Econômico: uma investigação sobre lucros, capital, crédito, juro e o ciclo econômico São Paulo: Nova Cultural,1988.

SOLÉ, Andreu. ¿Qué es una empresa ? Construcción de un idealtipo transdisciplinario. Working Paper. Paris, 2004.

2000. . Créateurs de mondes - nos possibles, nos impossibles. Paris: Éditions du Rocher, L'enterprisation du monde. In CHAIZE, J.; TORRES, F. Repenser l'entreprise: Saisir ce qui commence, vingt regards sur une idée neuve. Paris: Le Cherche Midi, 2008.

WEBER, Max. Economia e Sociedade. Brasília, DF: Editora Universidade de Brasília, 2004. Conceitos Básicos de Sociologia. São Paulo: Moraes, 1987. 